\title{
Unsteady squeezing flow of Cu-Al203 /water hybrid nanofluid in a horizontal channel with magnetic field
}

\author{
Najiyah Safwa Khashi'ie \\ Universiti Teknikal Malaysia Melaka, Hang Tuah Jaya \\ Iskandar Waini \\ Universiti Teknikal Malaysia Melaka, Hang Tuah Jaya \\ Norihan Md Arifin ( $\nabla$ norihana@upm.edu.my ) \\ Universiti Putra Malaysia \\ loan Pop \\ Babeş-Bolyai University
}

\section{Research Article}

Keywords: Hybrid nanofluid, Heat transfer, Horizontal channel, Magnetohydrodynamics, Squeezing flow

Posted Date: May 6th, 2021

DOl: https://doi.org/10.21203/rs.3.rs-489942/v1

License: (c) (i) This work is licensed under a Creative Commons Attribution 4.0 International License.

Read Full License

Version of Record: A version of this preprint was published at Scientific Reports on July 8th, 2021. See the published version at https://doi.org/10.1038/s41598-021-93644-4. 


\title{
Unsteady squeezing flow of $\mathrm{Cu}-\mathrm{Al}_{2} \mathrm{O}_{3} /$ water hybrid nanofluid in a horizontal channel with magnetic field
}

\author{
Najiyah Safwa Khashi'ie ${ }^{a}$, Iskandar Wainia, Norihan Md Arifin ${ }^{b^{*}}$, Ioan Pop \\ ${ }^{a}$ Fakulti Teknologi Kejuruteraan Mekanikal dan Pembuatan, Universiti Teknikal Malaysia \\ Melaka, Hang Tuah Jaya, 76100 Durian Tunggal, Melaka, Malaysia \\ ${ }^{b}$ Department of Mathematics, Faculty of Science, Universiti Putra Malaysia, 43400 UPM \\ Serdang, Selangor, Malaysia \\ ${ }^{\mathrm{c}}$ Department of Mathematics, Babeş-Bolyai University, 400084 Cluj-Napoca, Romania \\ *Corresponding author \\ E-mail address: norihana@upm.edu.my (N.M. Arifin)
}

\begin{abstract}
The proficiency of hybrid nanofluid from $\mathrm{Cu}-\mathrm{Al}_{2} \mathrm{O}_{3} /$ water formation as the heat transfer coolant is numerically analyzed using the powerful and user-friendly interface bvp4c in the Matlab software. For that purpose, the $\mathrm{Cu}-\mathrm{Al}_{2} \mathrm{O}_{3} /$ water nanofluid flow between two parallel plates is examined where the lower plate can be deformed while the upper plate moves towards/away from the lower plate. Another considerable factor are the wall mass suction/injection and the magnetic field which applied on the lower plate. The reduced ordinary (similarity) differential equations are solved using the bvp4c application. The validation of this novel model is conducted by comparing a few of numerical values for the reduced case of viscous fluid. The results imply the potency of this heat transfer fluid which can enhance the heat transfer performance for both upper and lower plates approximately by $7.10 \%$ and $4.11 \%$, respectively. An increase of squeezing parameter deteriorates the heat transfer coefficient by $4.28 \%$ (upper) and $5.35 \%$ (lower), accordingly. The rise of suction strength inflates the heat transfer at the lower plate while the presence of magnetic field shows reverse result.
\end{abstract}


Keywords: Hybrid nanofluid; Heat transfer; Horizontal channel; Magnetohydrodynamics; Squeezing flow

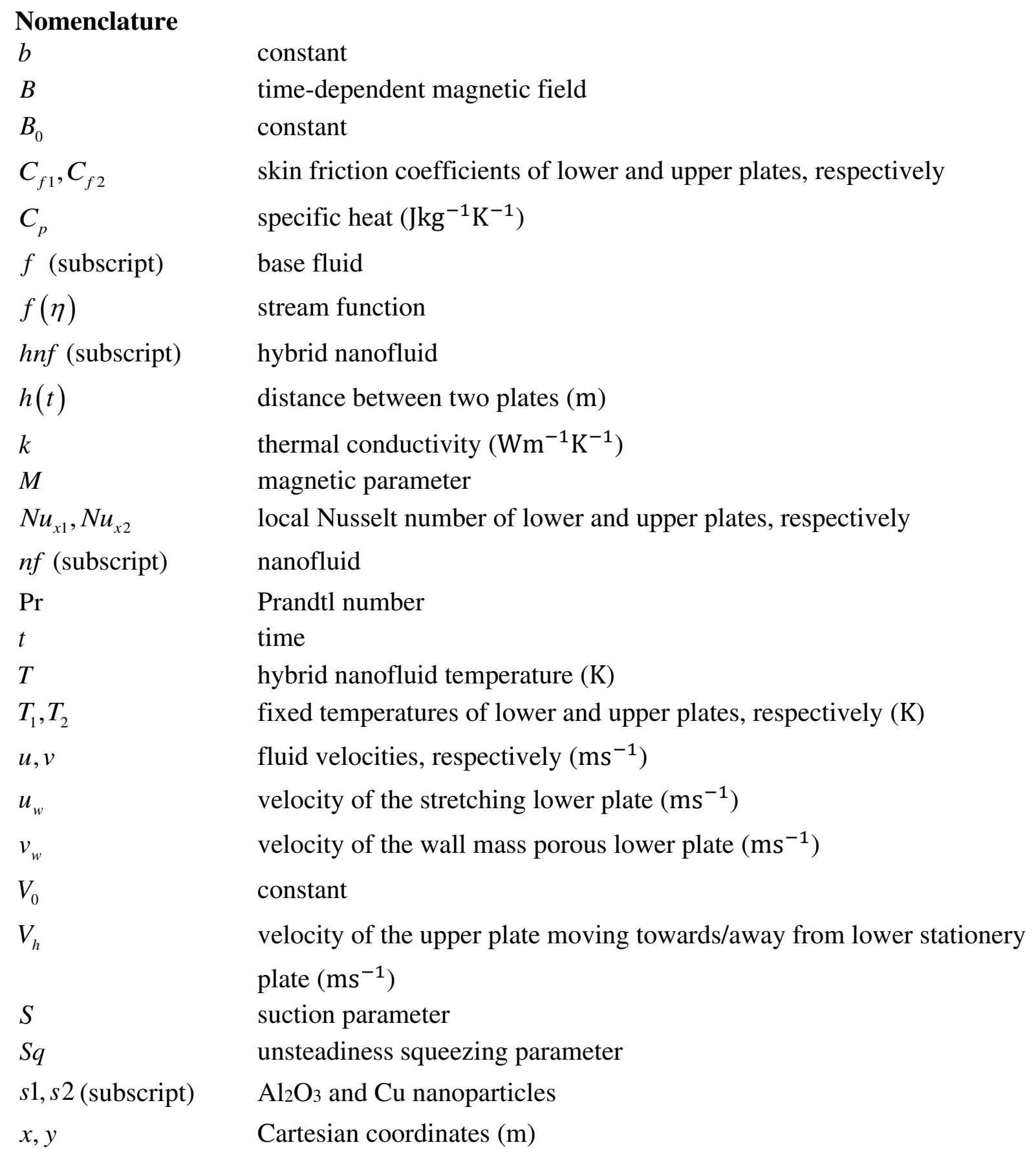

\section{Greek symbols}

$\begin{array}{ll}\phi_{1}, \phi_{2} & \text { concentrations for the nanoparticles } \\ \eta & \text { similarity variable } \\ \lambda & \text { stretching parameter } \\ \mu & \text { dynamic viscosity }\left(\mathrm{kgm}^{-1} \mathrm{~s}^{-1}\right)\end{array}$




$\begin{array}{ll}v & \text { kinematic viscosity }\left(\mathrm{m}^{2} \mathrm{~s}^{-1}\right) \\ \theta & \text { dimensionless fluid temperature } \\ \rho & \text { fluid density }\left(\mathrm{kgm}^{-3}\right) \\ \rho C_{p} & \text { heat capacity }\left(\mathrm{JK}^{-1} \mathrm{~m}^{-3}\right)\end{array}$

\section{Introduction}

The squeezing flow emerged from the moving boundaries is significant in the polymer processing, lubrication equipment, molding's injection and compression including the hydrodynamical machines. The connection between the squeezing flow and the loaded bearings' performance in engines including the phenomenon of adhesion has been highlighted by Jackson ${ }^{1}$. Stefan ${ }^{2}$ used lubrication approximation to initiate his work on squeezing flow. Meanwhile, another early works considering numerical scheme on the squeezing flow were studied by Verma ${ }^{3}$ and Singh et al. $^{4}$. Hamza ${ }^{5}$ inspected the squeezing flow and highlighted the impact of the suction and injection parameters. Another interesting papers reflecting the squeezing viscous flow have been debated in Ahmad et al. ${ }^{6}$, Shah et al. ${ }^{7}$, Khan et al. ${ }^{8}$, Magalakwe et al. ${ }^{9}$ and Basha $^{10}$.

The addition of single nanoparticle into a base working fluid is designed to enhance the base fluid's thermal conductivity which was initiated by Choi ${ }^{11}$. Meanwhile, the combination of a base fluid with suspended dissimilar nanoparticles is experimentally conducted to create hybrid nanofluid. The preparation including the thermophysical properties can be read from this papers ${ }^{12-19}$. The hybrid nanofluid's correlations by Takabi and Salehi ${ }^{20}$ and Devi and Devi ${ }^{21}$ were extensively used in the estimation of the thermophysical properties. The advantageous of hybrid nanofluid in augmenting the heat transfer performance could be found in these references $^{22-26}$.

Hence, this work aims to analyze the squeezing flow of hybrid nanofluid from $\mathrm{Cu}$ $\mathrm{Al}_{2} \mathrm{O}_{3} /$ water in the presence of magnetic field. Also, motivated by the interesting works in 
Raees et al. ${ }^{27}$ and Hayat et al. ${ }^{28,29}$, we assume that the lower plate is permeable and stretchable with a linear velocity. The single-phase mathematical model of $\mathrm{Cu}-\mathrm{Al}_{2} \mathrm{O}_{3} /$ water is formulated and then transformed into a reduced differential equations via the similarity transformation. The bvp4c application is used for the results' generation and validated based on the available numerical values from the previous works. This study is novel and original which consider an internal hybrid nanofluid flow.

\section{Mathematical Model}

\section{Physical assumptions and thermophysical correlations}

$\mathrm{Cu}-\mathrm{Al}_{2} \mathrm{O}_{3} /$ water formation is considered to flow between two infinite parallel plates, as shown in Fig. 1. The upper plate is placed at $y=h(t)=\sqrt{\frac{v_{f}(1-\alpha t)}{b}}$ from the lower plate, while the upper plate with velocity $V_{h}=\frac{d h(t)}{d t}=-\frac{\alpha}{2} \sqrt{\frac{v_{f}}{b(1-\alpha t)}}$ is moving towards (squeezing) the lower plate. Further assumption is the lower and upper plates are maintained at fixed temperatures $T_{1}$ and $T_{2}$, respectively. Meanwhile, the porous lower plate is included in the physical illustration for the possible fluid suction/injection with the wall mass velocity is denoted as $v_{w}=-\frac{V_{0}}{1-\alpha t} ; V_{0}>0$ for suction, $V_{0}<0$ for injection and $V_{0}=0$ corresponds to an impermeable plate. Also, the lower plate is stretchable with linear velocity $u_{w}=\frac{b x}{1-\alpha t} ; t<1 / \alpha$ while the inclusion of time-dependent magnetic field is formulated with $B=\frac{B_{0}}{1-\alpha t}$. 


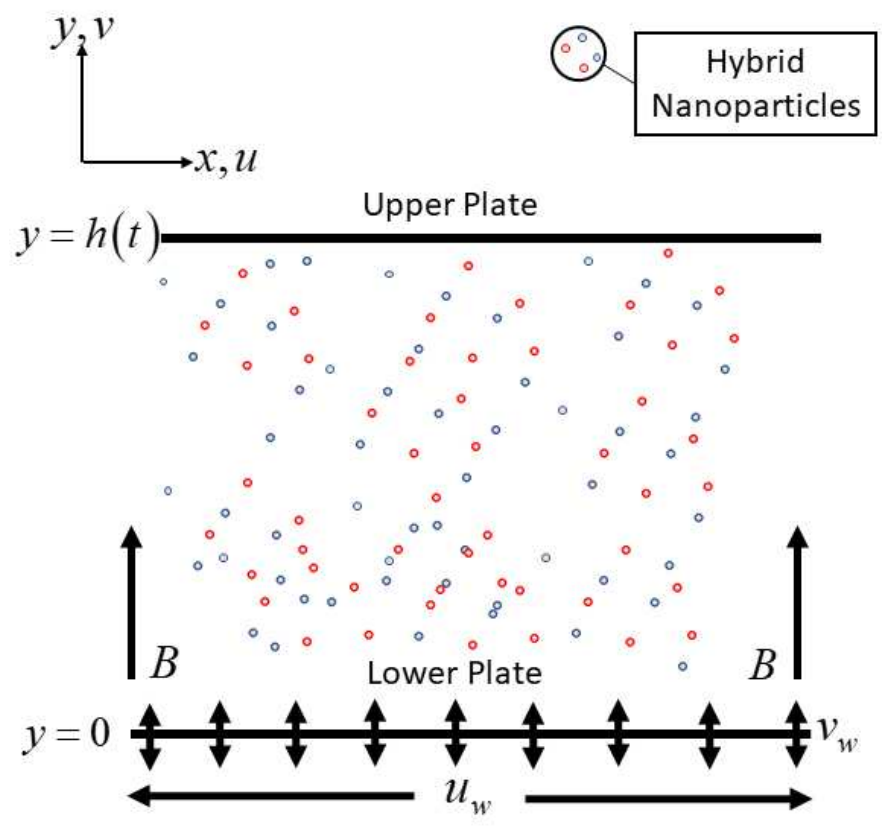

Fig. 1 Physical illustration with coordinate system

Under these assumptions and using the hybrid nanofluid model proposed by Takabi and Salehi $^{20}$, the governing conservation equations are ${ }^{27-29}$.

$$
\begin{aligned}
& \frac{\partial u}{\partial x}+\frac{\partial v}{\partial y}=0, \\
& \frac{\partial V}{\partial t}+u \frac{\partial V}{\partial x}+v \frac{\partial V}{\partial y}=\frac{\mu_{h n f}}{\rho_{h n f}} \frac{\partial^{2} V}{\partial y^{2}}-\frac{\sigma_{h n f}}{\rho_{h n f}} B^{2} V, \\
& \frac{\partial T}{\partial t}+u \frac{\partial T}{\partial x}+v \frac{\partial T}{\partial y}=\frac{k_{h n f}}{\left(\rho C_{p}\right)_{h n f}} \frac{\partial^{2} T}{\partial y^{2}},
\end{aligned}
$$

where $V=\frac{\partial v}{\partial x}-\frac{\partial u}{\partial y}$. The associate conditions at the lower and upper plates are (see Raees et al. ${ }^{27}$ and Hayat et al. ${ }^{28,30}$ )

$$
\begin{aligned}
& u=\lambda \frac{b x}{1-\alpha t}, \quad v=-\frac{V_{0}}{1-\alpha t}, \quad T=T_{1} \quad \text { at } \quad y=0 \quad \text { (lower plate) } \\
& u=0, \quad v=\frac{d h(t)}{d t}, \quad T=T_{2} \quad \text { at } \quad y=h(t) \quad \text { (upper plate) }
\end{aligned}
$$

Here $u$ and $v$ are the velocities along $x$ and $y$ directions and $T$ is the hybrid nanofluid temperature. For the evaluation of the thermophysical properties (see Table 1), we adopt the 
correlations by Takabi and Salehi ${ }^{20}$ which are feasible and correct based on the experimental validation. These correlations are built based on the physical assumptions. Meanwhile, Table 2 display the the physical properties of the pure water and nanoparticles.

Table 1 Hybrid nanofluid's correlations ${ }^{20}$.

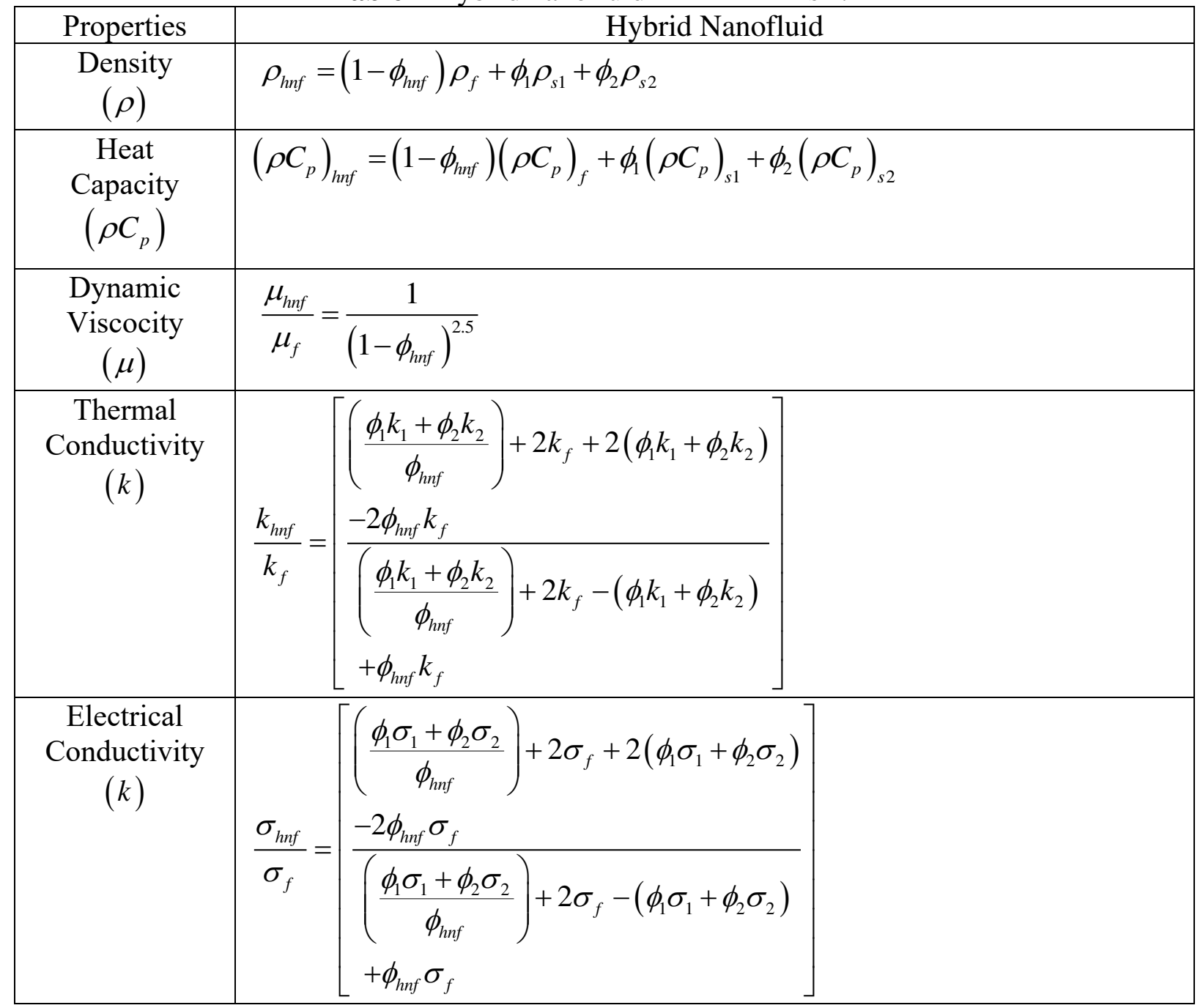

Table 2 Thermophysical properties for pure water and nanoparticles ${ }^{30}$.

\begin{tabular}{|c|c|c|c|}
\hline \multirow{2}{*}{ Thermophysical Properties } & \multirow{2}{*}{$\mathrm{H}_{2} \mathrm{O}$} & $\mathrm{Al}_{2} \mathrm{O}_{3}$ & $\mathrm{Cu}$ \\
\cline { 3 - 4 } & & 3970 & 8933 \\
\hline$\rho\left(\mathrm{kgm}^{-3}\right)$ & 997.1 & 765 & 385 \\
\hline$C_{p}\left(\mathrm{Jkg}^{-1} \mathrm{~K}^{-1}\right)$ & 4179 & 40 & 400 \\
\hline$k\left(\mathrm{Wm}^{-1} K^{-1}\right)$ & 0.6130 & & \\
\hline
\end{tabular}




\section{Reduced Differential Equations}

According to Raees et al. ${ }^{27}$ and Hayat et al. ${ }^{28,29}$, the suitable dimensionless variables are $\psi=\sqrt{\frac{b v_{f}}{1-\alpha t}} x f(\eta), \quad u=\frac{b x}{1-\alpha t} f^{\prime}(\eta), \quad v=-\sqrt{\frac{b v_{f}}{1-\alpha t}} f(\eta)$, $\eta=\sqrt{\frac{b}{v_{f}(1-\alpha t)}} y, \quad \theta(\eta)=\frac{T-T_{0}}{T_{2}-T_{0}}$

Hence, substituting (5) into Eqs. (2)-(4), the ODEs and boundary conditions are

$$
\begin{aligned}
& \left(\frac{\mu_{h n f} / \mu_{f}}{\rho_{h n f} / \rho_{f}}\right) f^{i v}+f f^{\prime \prime \prime}-f f^{\prime \prime}-\frac{S q}{2}\left(3 f^{\prime \prime}+\eta f^{\prime \prime \prime}\right)-\left(\frac{\sigma_{h n f} / \sigma_{f}}{\rho_{h n f} / \rho_{f}}\right) M f^{\prime \prime}=0, \\
& \frac{1}{\operatorname{Pr}} \frac{k_{h n f} / k_{f}}{\left(\rho C_{p}\right)_{h n f} /\left(\rho C_{p}\right)_{f}} \theta^{\prime \prime}+f \theta^{\prime}-\frac{S q}{2} \eta \theta^{\prime}=0, \\
& f^{\prime}(0)=\lambda, \quad f(0)=S, \quad \theta(0)=\delta, \\
& f^{\prime}(1)=0, \quad f(1)=\frac{S q}{2}, \quad \theta(1)=1 .
\end{aligned}
$$

where $\lambda>0$ refers to the stretching lower plate and $\lambda=0$ denotes the fixed/static lower plate. Another dimensionless parameters are the unsteadiness squeeze parameter $S q$, magnetic parameter $M$, suction parameter $S$, Prandtl number Pr and constant $\delta$. These parameters are defined as $^{27-29}$

$$
\operatorname{Pr}=\frac{\left(\rho C_{p}\right)_{f}}{k_{f}}, \quad S q=\frac{\alpha}{b}, \quad M=\frac{\sigma_{f} B_{0}}{b \rho_{f}}, \quad S=\frac{V_{0}}{b h}, \quad \delta=\frac{T_{1}-T_{0}}{T_{2}-T_{0}}
$$

In this work, we set $\delta=0$ which in accordance with Hayat et al. ${ }^{28,29}$. Further, we notice that Eq. (6) is compatible with the reduced momentum equation in Hayat et al. ${ }^{28}$ and Hayat et al. ${ }^{29}$ (if the couple stress parameter is zero) with the exclusion of the hybrid nanoparticles or $\phi_{1}, \phi_{2} \approx 0$ (regular fluid). The reduced skin friction coefficients and local Nusselt numbers at lower and upper plates are $27-29$

Lower: $\quad \operatorname{Re}_{x}^{1 / 2} C_{f 1}=\frac{\mu_{h n f}}{\mu_{f}} f^{\prime \prime}(0), \quad \quad$ Upper: $\quad \operatorname{Re}_{x}{ }^{1 / 2} C_{f 2}=\frac{\mu_{h n f}}{\mu_{f}} f^{\prime \prime}(1)$, 
Lower: $\quad \operatorname{Re}_{x}^{-1 / 2} N u_{x 1}=-\frac{k_{h n f}}{k_{f}} \theta^{\prime}(0), \quad \quad \operatorname{Re}_{x}^{-1 / 2} N u_{x 2}=-\frac{k_{h n f}}{k_{f}} \theta^{\prime}(1)$,

where $\operatorname{Re}_{x}=\frac{x U_{w}}{v_{f}}$

\section{Results and Discussion}

The bvp4c solver procurable in the Matlab software successfully used as the numerical computational tool in the entire work. Equations (6) to (8) are solved by transforming it first into the language of the bvp4c code as follows:

$$
\begin{aligned}
f= & y 1, \quad f^{\prime}=y 2, \quad f^{\prime \prime}=y 3, \quad f^{\prime \prime \prime}=y 4, \\
f^{i v} & =\left(\frac{\rho_{h n f} / \rho_{f}}{\mu_{h n f} / \mu_{f}}\right)\left(f f^{\prime \prime}-f f^{\prime \prime \prime}+\frac{S q}{2}\left(3 f^{\prime \prime}+\eta f^{\prime \prime \prime}\right)+\left(\frac{\sigma_{h n f} / \sigma_{f}}{\rho_{h n f} / \rho_{f}}\right) M f^{\prime \prime}\right), \\
& =\left(\frac{\rho_{h n f} / \rho_{f}}{\mu_{h n f} / \mu_{f}}\right)\left(y 2 y 3-y 1 y 4+\frac{S q}{2}(3 y 3+\eta y 4)+\left(\frac{\sigma_{h n f} / \sigma_{f}}{\rho_{h n f} / \rho_{f}}\right) M y 3\right),
\end{aligned}
$$

$\theta=y 5, \quad \theta^{\prime}=y 6$,

$$
\begin{aligned}
\theta^{\prime \prime} & =\operatorname{Pr}\left(\frac{\left(\rho C_{p}\right)_{h n f} /\left(\rho C_{p}\right)_{f}}{k_{h n f} / k_{f}}\right)\left(\frac{S q}{2} \eta \theta^{\prime}-f \theta^{\prime}\right), \\
& =\operatorname{Pr}\left(\frac{\left(\rho C_{p}\right)_{h n f} /\left(\rho C_{p}\right)_{f}}{k_{h n f} / k_{f}}\right)\left(\frac{S q}{2} \eta y 6-y 1 y 6\right),
\end{aligned}
$$

$f^{\prime}(0)=\lambda, \quad f(0)=S, \quad \theta(0)=\delta$,

$y a 2-\lambda, \quad y a 1-S, \quad y a 5-\delta$,

$f^{\prime}(1)=0, \quad f(1)=\frac{S q}{2}, \quad \theta(1)=1$,

$y b 2, \quad y b 1-\frac{S q}{2}, \quad y b 5-1$.

The results are generated and graphically presented for the distribution of the skin friction coefficients, velocity, heat transfer rates and temperature of both upper and lower plates. The 
value of the Prandtl number is fixed to 6.2 which indicates the use of water at $25^{\circ} \mathrm{C}$ while the initial temperature at lower plate's wall is represented by $\delta=0$ so that $\theta(0)=0$. Another parameters are controlled within the ranges of $0 \leq S q \leq 1$ (unsteadiness squeezing parameter), $-1.2 \leq S \leq 1.2$ (suction/injection parameter), $0 \leq \lambda \leq 2$ (stretching parameter) and $0 \leq M \leq 3$ (magnetic parameter). To further validate the precision of the present model, the numerical values are compared with Hayat et al. ${ }^{28,29}$ as displayed in Tables 3 and 4 which shows identical results.

Table 5 shows variety of $\operatorname{Re}_{x}^{1 / 2} C_{f 1}, \operatorname{Re}_{x}^{1 / 2} C_{f 2},-\operatorname{Re}_{x}^{-1 / 2} N u_{x 1}$ and $-\operatorname{Re}_{x}^{-1 / 2} N u_{x 2}$. With the consideration of viscous fluid, lower static plate and the exclusion of magnetic, suction/injection and squeezing parameters, the internal flow have zero frictions and equal heat transfer rates at both plates. The observation in Table 5 shows that as the stretching parameter increases from $\lambda=0$ to $\lambda=1,-\operatorname{Re}_{x}^{-1 / 2} N u_{x 1}$ increases, but the stretching lower plate tends to increase $\operatorname{Re}_{x}{ }^{1 / 2} C_{f 1}$. Further, we analyze for four types of fluids: viscous/water $\left(\phi_{1}, \phi_{2}=0\right)$, $\mathrm{Al}_{2} \mathrm{O}_{3}$-water $\quad\left(\phi_{1}=0.01, \phi_{2}=0\right), \quad \mathrm{Cu}$-water $\quad\left(\phi_{1}=0, \phi_{2}=0.01\right) \quad$ and $\mathrm{Cu}-\mathrm{Al}_{2} \mathrm{O}_{3} /$ water $\left(\phi_{1}, \phi_{2}=0.01\right)$ which reveals that the $\mathrm{Cu}-\mathrm{Al}_{2} \mathrm{O}_{3} /$ water has the highest heat transfer coefficients at both plates followed by the $\mathrm{Cu}$-water, $\mathrm{Al}_{2} \mathrm{O}_{3}$-water and water. This implies the suitability of $\mathrm{Cu}-\mathrm{Al}_{2} \mathrm{O}_{3} /$ water hybrid nanofluid as the effective coolant in the engineering/technology appliances. Since the inclusion of the squeezing parameter can reduce the heat transfer rate at both plates, it is useful to know the exact parameters which can assist the heat transfer performance for this situation. In Table 6, we analyze the difference percentage of the heat transfer rate at both upper and lower plate which can be used for future assessment by other engineers or researchers. This analysis also can help in determining the preferable strength of the parameters either in the augmentation or reduction of the heat transfer in both locations. 
Table 3 Comparative values of $f^{\prime \prime}(0)$-lower plate and $f^{\prime \prime}(1)$-upper plate when $S q=0$, $\lambda=1, \phi_{1}, \phi_{2}=0$ with various $S$ and $M$.

\begin{tabular}{cccccc}
\hline & \multicolumn{4}{c}{$f^{\prime \prime}(0)$} & \multicolumn{2}{c}{$f^{\prime \prime}(1)$} \\
& $S$ & \multicolumn{1}{c}{ Present } & Hayat et al. ${ }^{29}$ & Present & Hayat et al. $^{29}$ \\
\cline { 3 - 6 } & & -7.4111525 & -7.411153 & 4.7133028 & 4.713303 \\
1 & 0.5 & -7.5916177 & -7.591618 & 4.7390165 & 4.739017 \\
4 & 0.5 & -8.1103342 & -8.110334 & 4.8202511 & 4.820251 \\
9 & 0.5 & -8.9100956 & -8.910096 & 4.9648698 & 4.964870 \\
4 & 0.0 & -4.5878911 & -4.587891 & 1.8424469 & 1.842447 \\
4 & 0.3 & -6.6656620 & -6.665662 & 3.6536948 & 3.653695 \\
4 & 0.6 & -8.8514442 & -8.851444 & 5.3912475 & 5.391248 \\
4 & 1.0 & -11.9485843 & -11.948584 & 7.5934262 & 7.593426 \\
\hline
\end{tabular}

Table 4 Comparative values of $f^{\prime \prime}(1)$-upper plate when $\lambda=1$ and $\phi_{1}, \phi_{2} \approx 0$ with various $S$, $S q$ and $M$.

\begin{tabular}{|c|c|c|c|c|}
\hline \multirow{2}{*}{$M$} & \multirow{2}{*}{$S q$} & \multirow{2}{*}{$S$} & \multicolumn{2}{|c|}{$f^{\prime \prime}(1)$} \\
\hline & & & Present & Hayat et al. ${ }^{28}$ \\
\hline 0 & 1 & 0.5 & 1.814634 & 1.81463 \\
\hline 0.25 & 1 & 0 & -1.171551 & -1.17155 \\
\hline 0.25 & 1 & 0.5 & 1.808177 & 1.80818 \\
\hline 0.25 & 0 & 0.5 & 4.719656 & 4.79166 \\
\hline 0.25 & 1.5 & 0.5 & 0.283948 & 0.28395 \\
\hline 0.25 & 1 & 1 & 4.573016 & 4.57302 \\
\hline 1 & 1 & 0.5 & 1.789372 & 1.78937 \\
\hline
\end{tabular}


Table 5 Numerical values of $\operatorname{Re}_{x}^{1 / 2} C_{f 1}, \operatorname{Re}_{x}^{1 / 2} C_{f 2},-\operatorname{Re}_{x}{ }^{-1 / 2} N u_{x 1}$ and $-\operatorname{Re}_{x}{ }^{-1 / 2} N u_{x 2}$ with various values of the control parameters.

\begin{tabular}{cccccccccc}
\hline$S q$ & $M$ & $S$ & $\phi_{1}$ & $\phi_{2}$ & $\lambda$ & $\mathrm{Re}_{x}^{1 / 2} C_{f 1}$ & $\mathrm{Re}_{x}^{1 / 2} C_{f 2}$ & $-\mathrm{Re}_{x}{ }^{-1 / 2} N u_{x 1}$ & $-\mathrm{Re}_{x}{ }^{-1 / 2} N u_{x 2}$ \\
\hline 0 & 0 & 0 & 0 & 0 & 0 & 0 & 0 & 1 & 1 \\
0 & 0 & 0 & 0 & 0 & 0.5 & -2.021410 & 0.988195 & 1.161853 & 0.898716 \\
0 & 0 & 0 & 0 & 0 & 1 & -4.085563 & 1.953179 & 1.336614 & 0.802165 \\
0 & 0 & 0 & 0.01 & 0 & 1 & -4.189890 & 2.002674 & 1.363747 & 0.831425 \\
0 & 0 & 0 & 0 & 0.01 & 1 & -4.194140 & 2.000385 & 1.365114 & 0.832586 \\
0 & 0 & 0 & 0.01 & 0.01 & 1 & -4.302130 & 2.051712 & 1.393870 & 0.863450 \\
1 & 0 & 0 & 0.01 & 0.01 & 1 & -1.240570 & -1.220273 & 1.323125 & 0.828030 \\
1 & 1 & 0 & 0.01 & 0.01 & 1 & -1.322328 & -1.301313 & 1.318921 & 0.831390 \\
1 & 1 & 0.2 & 0.01 & 0.01 & 1 & -2.688739 & -0.003914 & 1.893656 & 0.668863 \\
1 & 1 & -0.2 & 0.01 & 0.01 & 1 & -0.003540 & -2.635965 & 0.887339 & 1.001950 \\
\hline
\end{tabular}

Table 6 Heat transfer analysis with the addition of the control parameters.

\begin{tabular}{ccccc}
\hline Parameters & $\begin{array}{c}\text { Develop/reduce } \\
\text { the thermal rate } \\
\text { at lower plate }\end{array}$ & $\begin{array}{c}\text { Difference } \\
\text { percentage of } \\
-\operatorname{Re}_{x}^{-1 / 2} N u_{x 1}\end{array}$ & $\begin{array}{c}\text { Develop/reduce } \\
\text { the thermal rate } \\
\text { at upper plate }\end{array}$ & $\begin{array}{c}\text { Difference } \\
\text { percentage of } \\
-\mathrm{Re}_{x}^{-1 / 2} N u_{x 2}\end{array}$ \\
\hline Squeezing $(S q)$ & Reduce & $-5.35 \%$ & Reduce & $-4.28 \%$ \\
Magnetic $(M)$ & Reduce & $-0.32 \%$ & Develop & $0.40 \%$ \\
Suction $(S>0)$ & Develop & $30.35 \%$ & Reduce & $-24.30 \%$ \\
Injection $(S<0)$ & Reduce & $-48.64 \%$ & Develop & $17.02 \%$
\end{tabular}

The exploration of pertinent parameters' impact such as squeezing, suction/injection and stretching parameters are continued with the observation on $f^{\prime}(\eta)$ and $\theta(\eta)$ as displayed in Figs. 2-7. In Fig. 2, the velocity distribution enhances with the addition of unsteadiness squeezing parameter. As the squeezing parameter's magnitude increases up to $S q=1$, the velocity distribution is depreciated at the upper plate. This is due to the squeezing effect which 
originated from the upper plate. However, the temperature profile in Fig. 3 slightly reduces near to the lower plate $(\eta<0.5)$ while increases near to the upper plate $(\eta>0.5)$.

Further, the impact of suction/injection parameter on both profiles is visualized in Figs. 4 and 5. As the suction/injection parameter increases from injection to suction $(S=-1.2,-0.2,0,0.2,1.2)$, the velocity profile decreases which reflects the higher magnitude of suction strength can reduce the velocity distribution. Since the suction is applied through the lower permeable plate, the velocity lessens while increases near to the upper plate. The temperature profile augments at both locations (lower and upper plate). Figures 6 and 7 present the plots of velocity and temperature distribution with variety values of the stretching parameter. The velocity gradually increases when $\eta<0.3$ while a contrary observation is obtained for $\eta>0.3$. The temperature profile increases for both lower and upper plates.

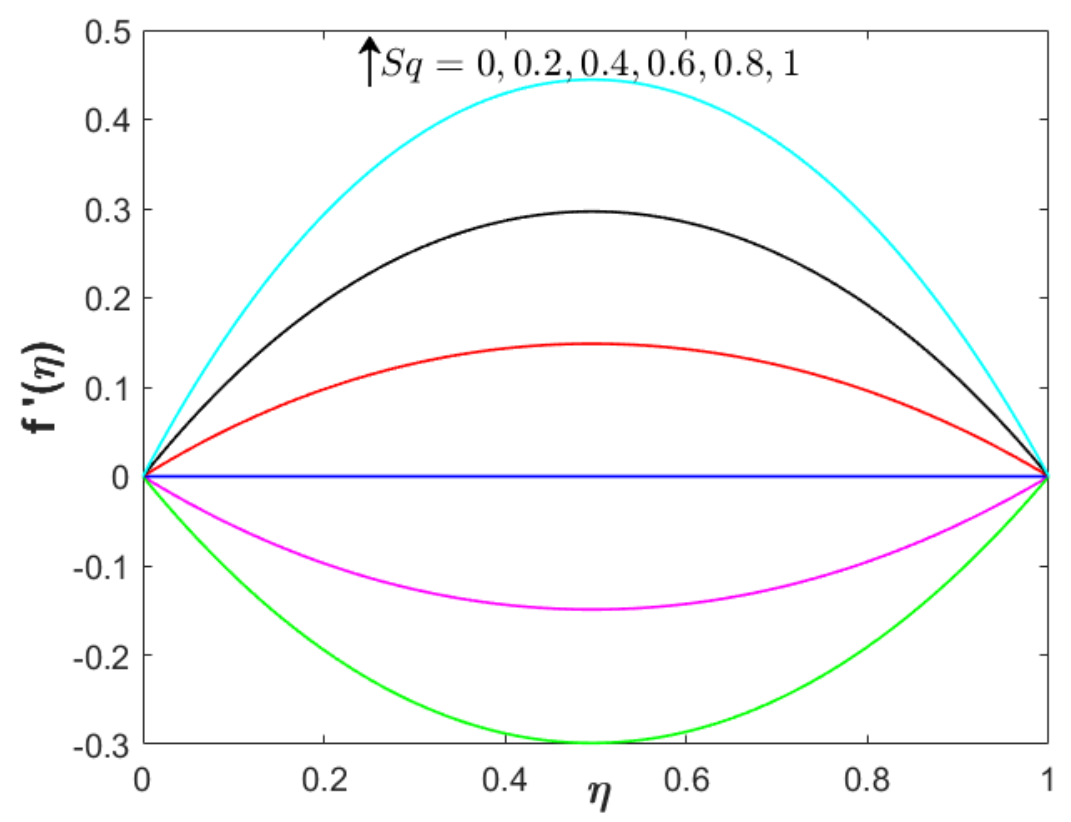

Fig. 2 Effect of squeezing parameter on $f^{\prime}(\eta)$ when $S=0.2, \lambda=0, M=1$ and $\phi_{1}=\phi_{2}=0.01$. 


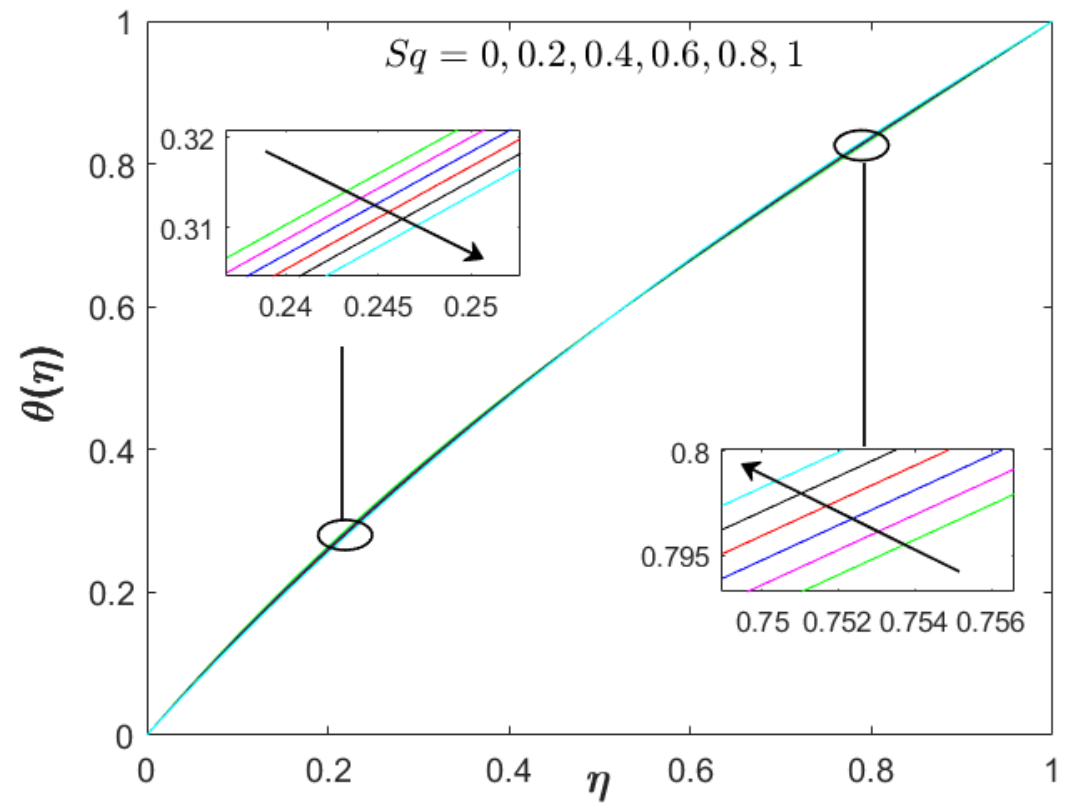

Fig. 3 Effect of squeezing parameter on $\theta(\eta)$ when $S=0.2, \lambda=0, S q=M=1$ and $\phi_{1}=\phi_{2}=0.01$

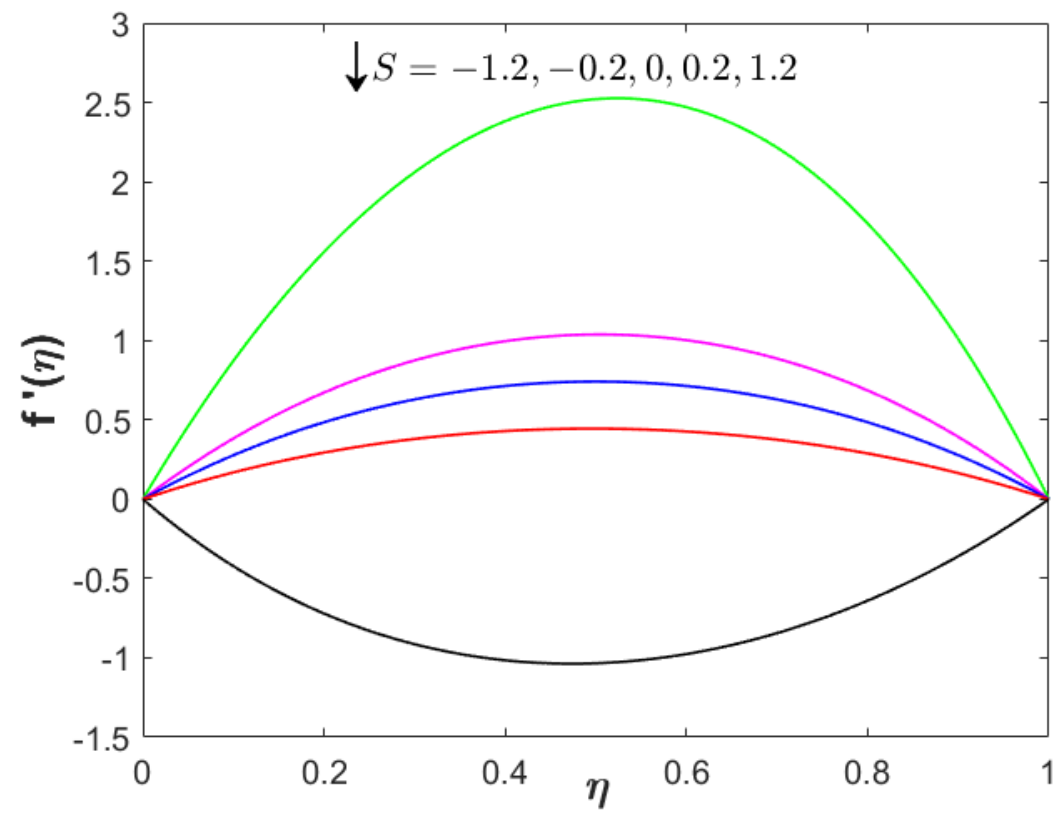

Fig. 4 Effect of suction/injection parameter on $f^{\prime}(\eta)$ when $\lambda=0, S q=M=1$ and $\phi_{1}=\phi_{2}=0.01$. 


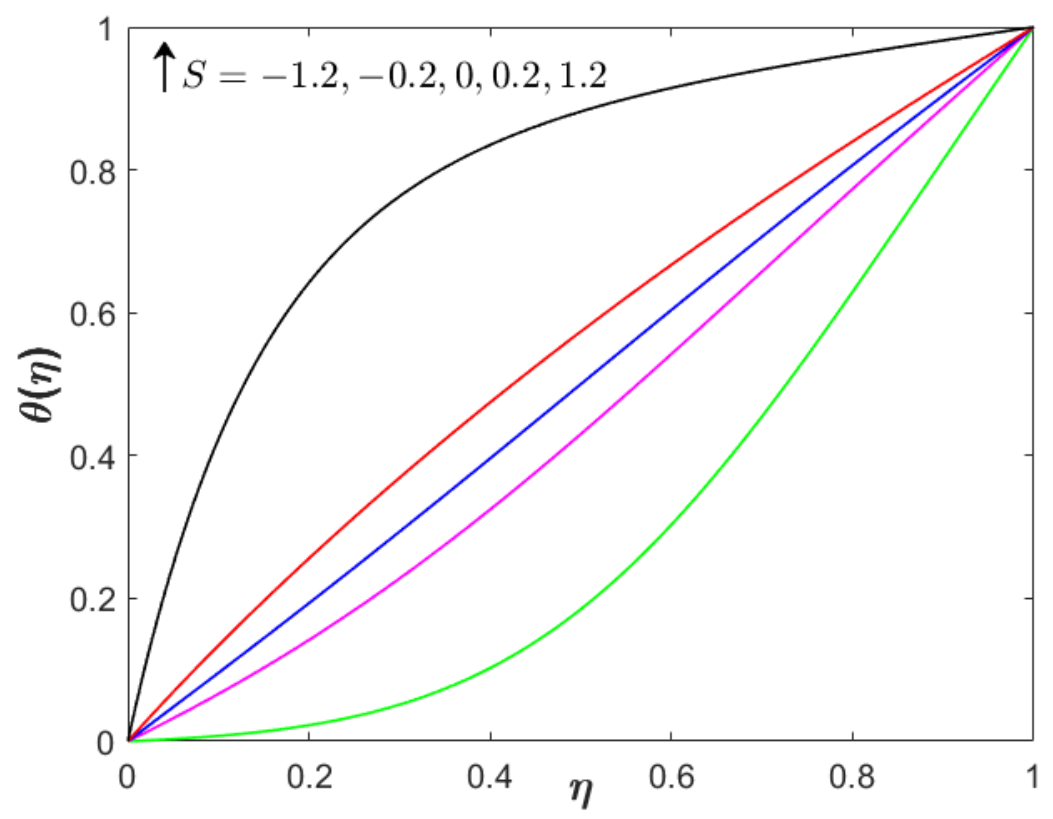

Fig. 5 Effect of suction/injection parameter on $\theta(\eta)$ when $\lambda=0, S q=M=1$ and $\phi_{1}=\phi_{2}=0.01$.

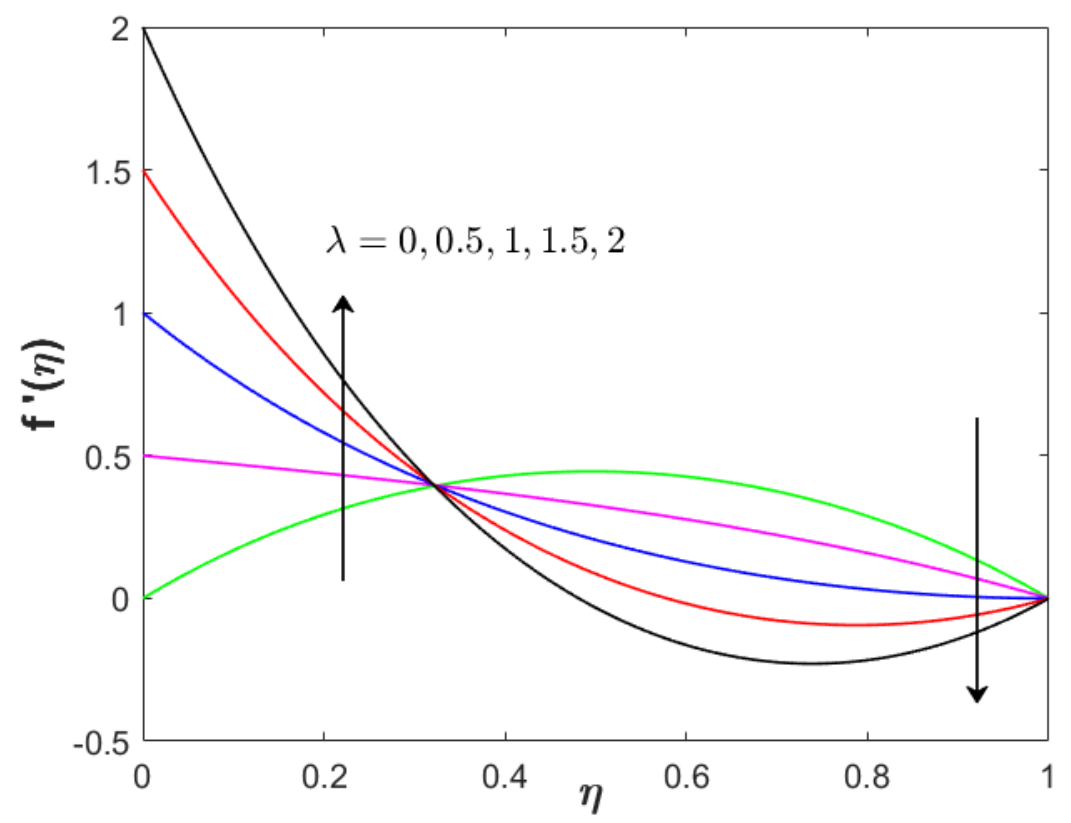

Fig. 6 Effect of stretching parameter on $f^{\prime}(\eta)$ when $S=0.2, S q=M=1$ and $\phi_{1}=\phi_{2}=0.01$. 


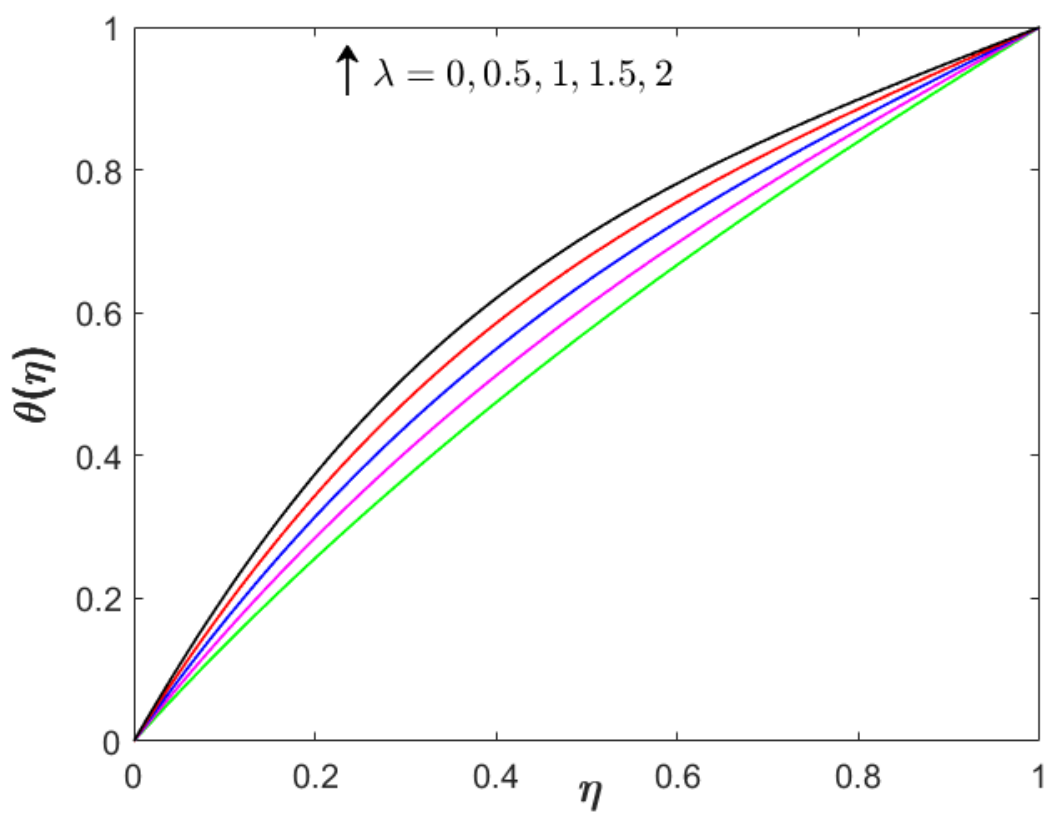

Fig. 7 Effect of stretching parameter on $\theta(\eta)$ when $S=0.2, S q=M=1$ and $\phi_{1}=\phi_{2}=0.01$.

\section{Conclusion}

This novel work presents a numerical study of $\mathrm{Cu}-\mathrm{Al}_{2} \mathrm{O}_{3} /$ water inside two plates (parallel lower and upper) with the appearance of magnetic field. The lower plate is permeable for the suction/injection processes and also can be stretched. Meanwhile, the upper plate can move towards the lower plate and creates the squeezing flow phenomenon. The mathematical model which suits this physical phenomenon follows the usual approximations of boundary layer flow while the bvp4c programme is fully utilized for the generation of the results. The distribution of $\operatorname{Re}_{x}^{1 / 2} C_{f 1}, \operatorname{Re}_{x}^{1 / 2} C_{f 2},-\operatorname{Re}_{x}^{-1 / 2} N u_{x 1}$ and $-\operatorname{Re}_{x}^{-1 / 2} N u_{x 2}$ are examined. The heat transfer rate of the lower plate reduces with the increase of magnetic, squeezing and injection parameters. However, about $30.35 \%$ of $-\operatorname{Re}_{x}^{-1 / 2} N u_{x 1}$ is developed with the inclusion of suction. Meanwhile, the enhancement of magnetic and injection parameters can lead to the development of upper plate's heat transfer performance. Another observation is conducted for the distribution of the velocity and temperature profiles. The addition of squeezing and 
stretching parameters can increase the velocity profile whereas high suction's magnitude shows opposite trend.

\section{Author contributions}

NSK conducted the numerical computation and wrote the manuscript, IW conducted the numerical computation and validated the solutions, NMA and IP formulated the problem and provided the literature review.

\section{Acknowledgements}

We acknowledge the KPT/FRGS/1/2019/STG06/UPM/02/3-Vot 5540309 from MOHE (Malaysia) including UTeM and UPM.

\section{Additional information}

Competing interests: The authors declare no competing interests.

\section{References}

1. Jackson, J.D. A study of squeezing flow. Appl. Sci. Res. 11(1), 148-52 (1963).

2. Stefen, M.J. Versuch Uber die scheinbare adhesion. Sitzungsberichte der Akademie der Wissenschaften in Wien. Mathematik-Naturwissen 69, 713-21 (1874).

3. Verma, R.L. A numerical solution for squeezing flow between parallel channels. Wear 72(1), 89-95 (1981).

4. Singh P., Radhakrishnan, V. \& Narayan, K.A. Squeezing flow between parallel plates. Ingenieur-Archiv. 60(4), 274-81 (1990).

5. Hamza, E.A. Suction and injection effects on a similar flow between parallel plates. $J$. Phys. D-Appl. Phys. 32(6), 656 (1999).

6. Ahmad, S., Khan, M.I., Hayat, T., Khan, M.I. \& Alsaedi, A. Entropy generation optimization and unsteady squeezing flow of viscous fluid with five different shapes of nanoparticles. Colloid Surf. A-Physicochem. Eng. Asp. 554, 197-210 (2018). 
7. Shah, R.A., Khan, A. \& Shuaib, M. Analysis of squeezing flow of a viscous fluid between corotating discs with Soret and Dufour effects. Heat Transf. Res. 49(11), (2018).

8. Khan, M.I., Ahmad, S., Hayat, T. \& Alsaedi, A. Entropy generation and activation energy impact on radiative flow of viscous fluid in presence of binary chemical reaction. Int. J. Chem. React. Eng. 16(9), (2018).

9. Magalakwe, G., Lekoko, M.L., Modise, K. \& Khalique, C.M. Lie group analysis for MHD squeezing flow of viscous fluid saturated in porous media. Alexandria Eng. J. 58(3), 1001-10 (2019).

10. Basha, H. A generalized perspective of magnetized radiative squeezed flow of viscous fluid between two parallel disks with suction and blowing. Heat Transf. 49(4), 224881 (2020).

11. Choi, S.U.S. Enhancing thermal conductivity of fluids with nanoparticle. Proc. ASME Int. Mech. Eng. Cong. Expo. FED 231/MD66, 99-105 (1995).

12. Sarkar, J., Ghosh, P. \& Adil, A. A review on hybrid nanofluids: recent research, development and applications. Renew. Sust. Energ. Rev. 43, 164-77 (2015).

13. Jana, S., Salehi-Khojin, A. \& Zhong WH. Enhancement of fluid thermal conductivity by the addition of single and hybrid nano-additives. Thermochim. Acta 462(1-2), 45-55 (2007).

14. Suresh, S., Venkitaraj, K.P., Selvakumar, P. \& Chandrasekar, M. Effect of $\mathrm{Al}_{2} \mathrm{O}_{3}-$ Cu/water hybrid nanofluid in heat transfer. Exp. Therm. Fluid Sci. 38, 54-60 (2012).

15. Sidik, N.A, Adamu, I.M., Jamil, M.M., Kefayati, G.H., Mamat, R. \& Najafi, G. Recent progress on hybrid nanofluids in heat transfer applications: a comprehensive review. Int. Comm. Heat Mass Transf. 78, 68-79 (2016).

16. Xian, H.W., Sidik, N.A. \& Saidur, R. Impact of different surfactants and ultrasonication time on the stability and thermophysical properties of hybrid nanofluids. Int. Comm. Heat Mass Transf. 110, 104389 (2020).

17. Sundar, L.S., Sharma, K.V., Singh, M.K. \& Sousa, A.C. Hybrid nanofluids preparation, thermal properties, heat transfer and friction factor-a review. Renew. Sust. Energ. Rev. 68, 185-98 (2017).

18. Babu, J.R., Kumar, K.K. \& Rao, S.S. State-of-art review on hybrid nanofluids. Renew. Sust. Energ. Rev. 77, 551-65 (2017). 
19. Sajid, M.U. \& Ali, H.M. Thermal conductivity of hybrid nanofluids: a critical review. Int. J Heat Mass Transf. 126, 211-34 (2018).

20. Takabi, B. \& Salehi, S. Augmentation of the heat transfer performance of a sinusoidal corrugated enclosure by employing hybrid nanofluid. Adv. Mech. Eng. 6, 147059 (2014).

21. Devi, S.A. \& Devi, S.S. Numerical investigation of hydromagnetic hybrid $\mathrm{Cu}-$ $\mathrm{Al}_{2} \mathrm{O}_{3} /$ water nanofluid flow over a permeable stretching sheet with suction. Int. J. Nonlin. Sci. Numer. Simul. 17(5), 249-57 (2016).

22. Zainal, N.A., Nazar, R., Naganthran, K. \& Pop, I. Unsteady EMHD stagnation point flow over a stretching/shrinking sheet in a hybrid $\mathrm{Al}_{2} \mathrm{O}_{3}-\mathrm{Cu} / \mathrm{H}_{2} \mathrm{O}$ nanofluid. Int. Comm. Heat Mass Transf. 123, 105205 (2021).

23. Zainal, N.A., Nazar, R., Naganthran, K. \& Pop, I. Unsteady three-dimensional MHD nonaxisymmetric homann stagnation point flow of a hybrid nanofluid with stability analysis. Mathematics 8(5), 784 (2020).

24. Khashi'ie, N.S., Arifin, N.M., Merkin, J.H., Yahaya, R.I. \& Pop, I. Mixed convective stagnation point flow of a hybrid nanofluid toward a vertical cylinder. Int. J. Numer. Methods Heat Fluid Flow (2021). https://doi.org/10.1108/HFF-11-2020-0725.

25. Khashi'ie, N.S., Hafidzuddin, E.H., Arifin, N.M. \& Wahi, N. Stagnation point flow of hybrid nanofluid over a permeable vertical stretching/shrinking cylinder with thermal stratification effect. CFD Lett. 12(2), 80-94 (2020).

26. Khashi'ie, N.S., Arifin, N.M., Pop, I. \& Nazar, R. Melting heat transfer in hybrid nanofluid flow along a moving surface, J. Therm. Anal. Calorim. (2020). https://doi.org/10.1007/s10973-020-10238-4.

27. Raees, A., Xu, H. \& Liao, S.J. Unsteady mixed nano-bioconvection flow in a horizontal channel with its upper plate expanding or contracting, Int. J. Heat Mass Transf. 86, 174-82 (2015).

28. Hayat, T., Muhammad, T., Qayyum, A., Alsaedi, A. \& Mustafa, M. On squeezing flow of nanofluid in the presence of magnetic field effects. J. Mol. Liq. 213, 179-85 (2016).

29. Hayat, T., Sajjad, R, Alsaedi, A., Muhammad, T. \& Ellahi, R. On squeezed flow of couple stress nanofluid between two parallel plates. Results Phys. 7, 553-61 (2017).

30. Oztop, H.F. \& Abu-Nada, E. Numerical study of natural convection in partially heated rectangular enclosures filled with nanofluids. Int. J. Heat Fluid Flow 29(5), 1326-36 (2008). 
Figures

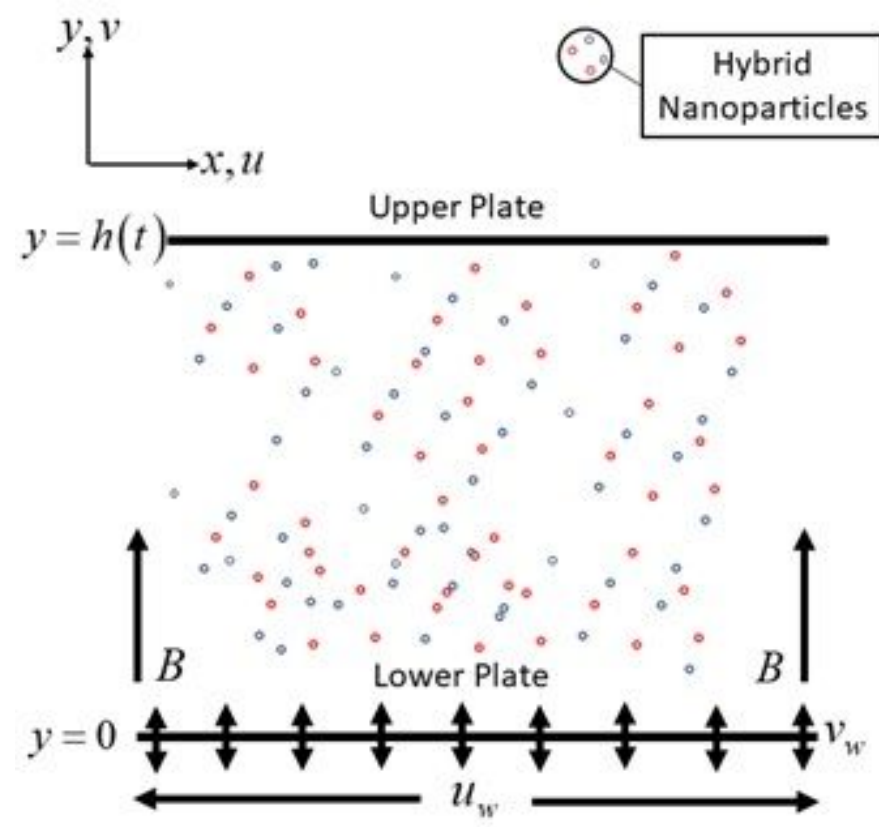

Figure 1

(See Manuscript file for Figure caption)

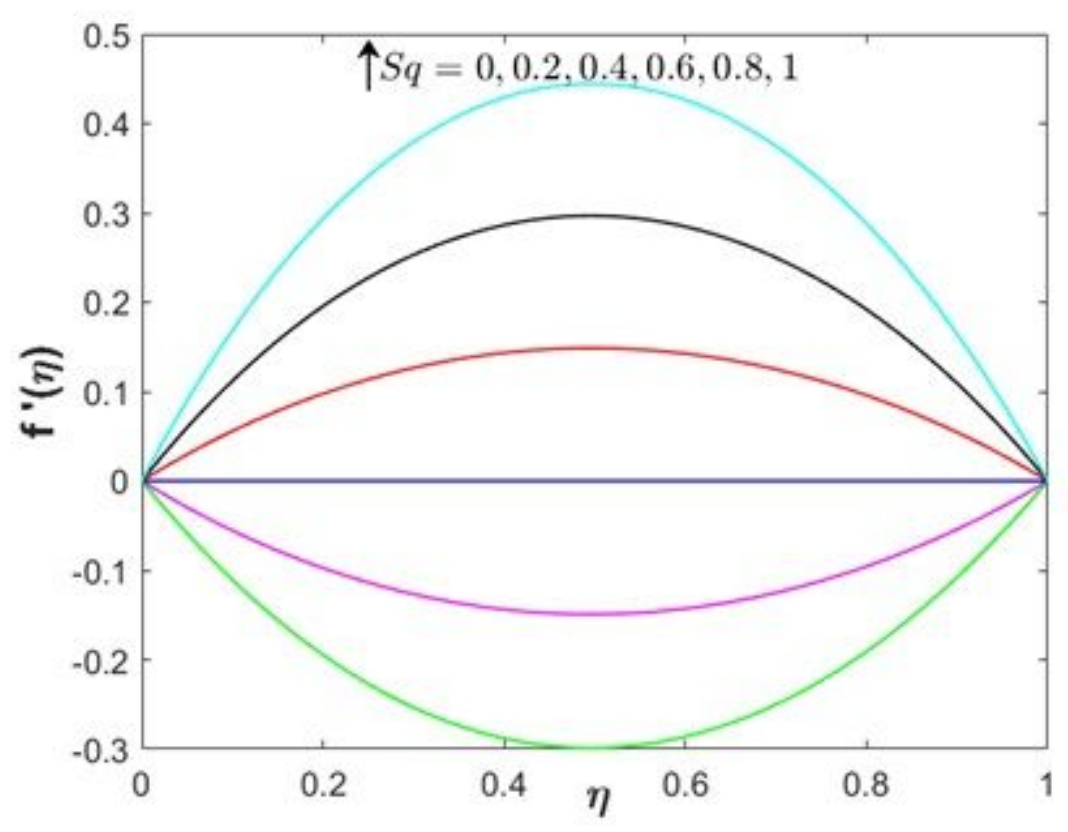

Figure 2

(See Manuscript file for Figure caption) 


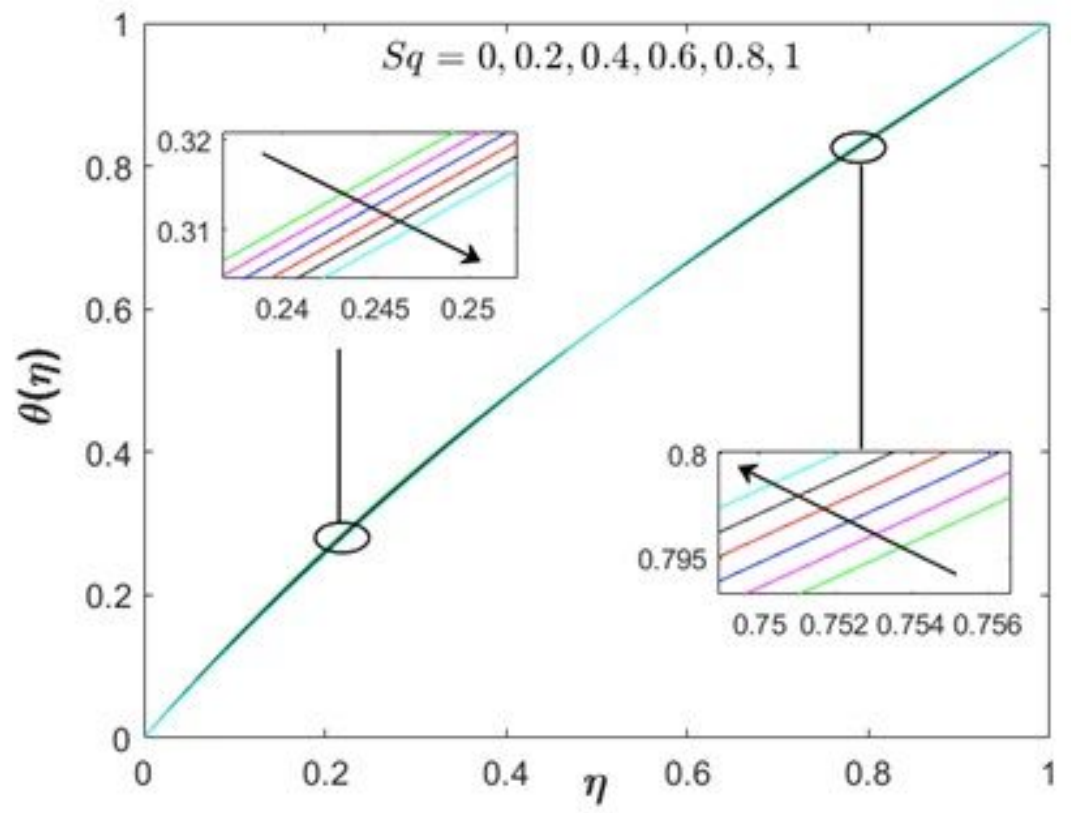

Figure 3

(See Manuscript file for Figure caption)

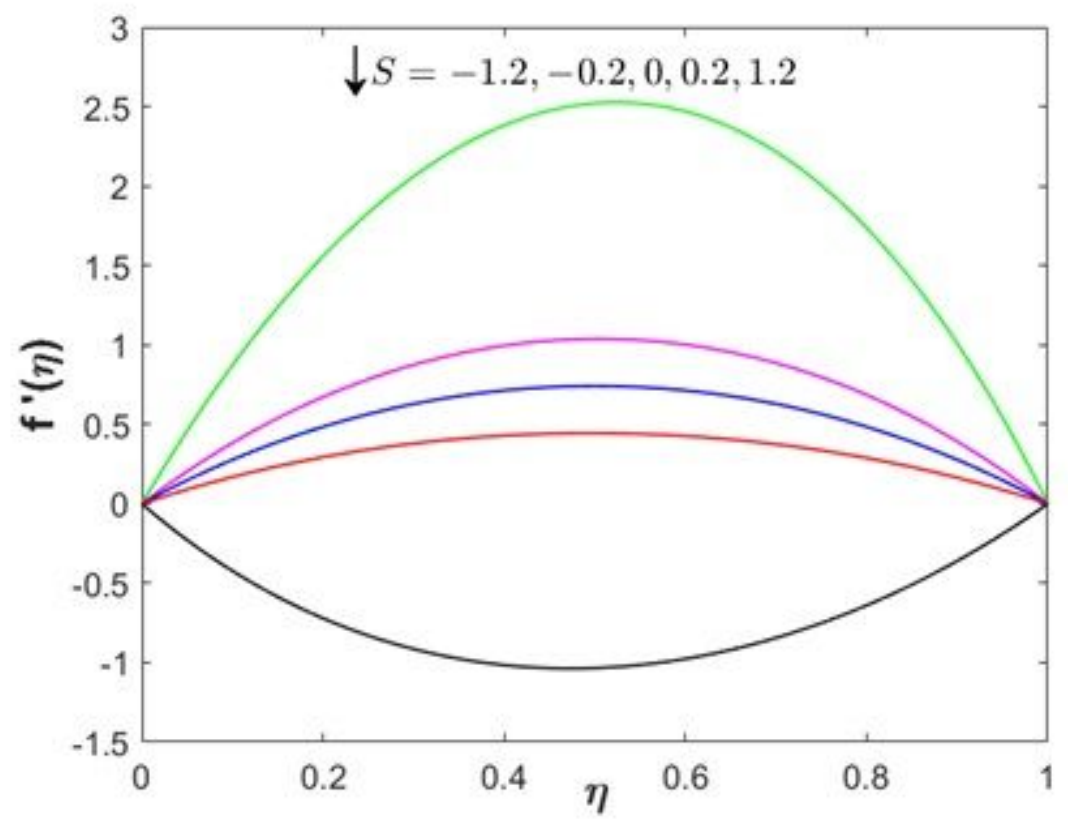

Figure 4

(See Manuscript file for Figure caption) 


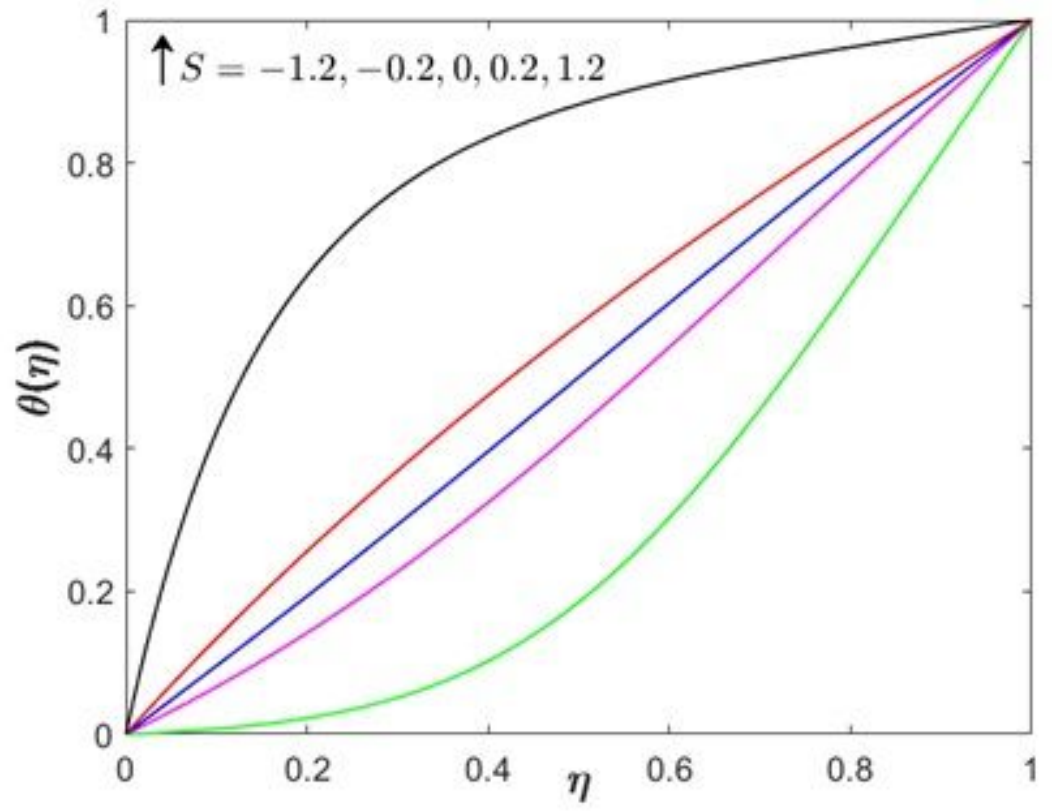

Figure 5

(See Manuscript file for Figure caption)

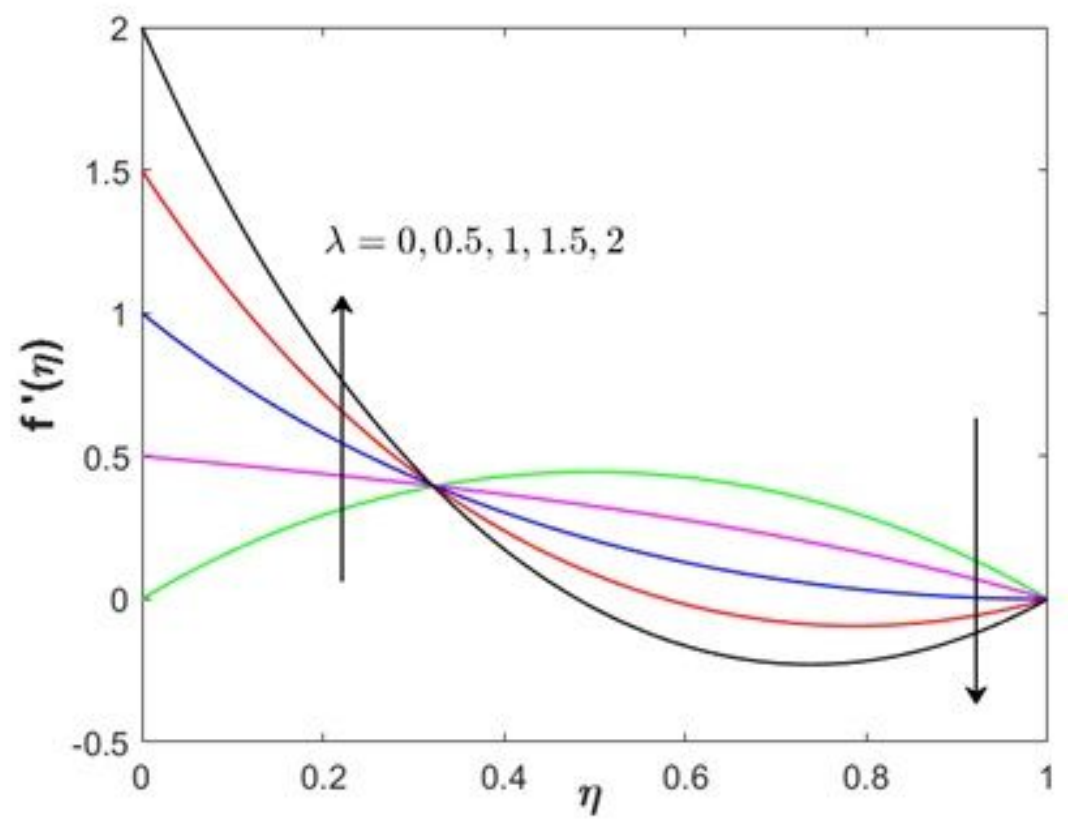

Figure 6

(See Manuscript file for Figure caption) 


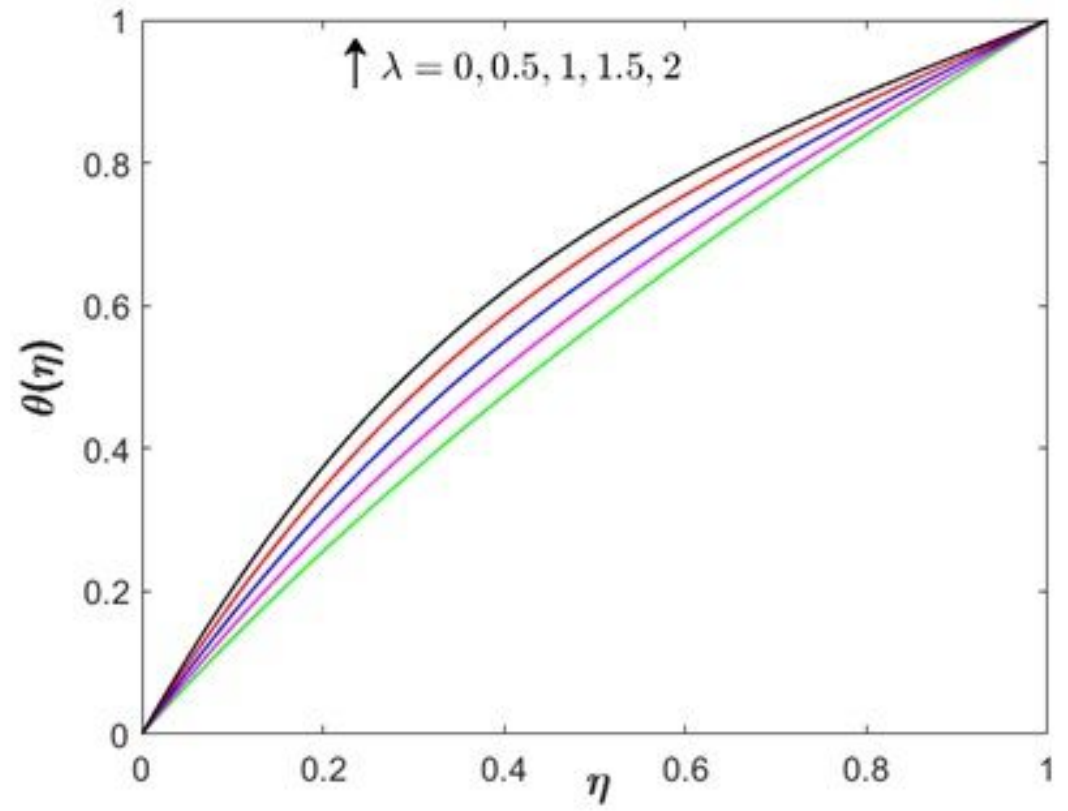

Figure 7

(See Manuscript file for Figure caption) 